Research Article

\title{
Coupling Effect of Creep Deformation and Prestress Loss of Anchored Jointed Rock
}

\author{
Bairu Zhu $\mathbb{D D}^{1}{ }^{1}$ Yang Song, ${ }^{2}$ Heping Wang, ${ }^{1}$ and Yongqi $\mathrm{Li}^{1}$ \\ ${ }^{1}$ School of Civil Engineering, Liaoning Technical University, Fuxin, Liaoning 123000, China \\ ${ }^{2}$ College of Architecture and Transportation, Liaoning Technical University, Fuxin, Liaoning 123000, China
}

Correspondence should be addressed to Bairu Zhu; zhubairu6@126.com

Received 20 June 2020; Revised 30 August 2020; Accepted 1 September 2020; Published 10 September 2020

Academic Editor: Fengqiang Gong

Copyright (c) 2020 Bairu Zhu et al. This is an open access article distributed under the Creative Commons Attribution License, which permits unrestricted use, distribution, and reproduction in any medium, provided the original work is properly cited.

To explore the variation behaviour of anchor jointed rock subject to high in situ stress states, a coupling effect calculation model based on stress equality was established based on the original rheological model of rock by combining element combination theory and experiment, and the model was verified. The coupling effect between rock mass creep and bolt prestress loss is established by setting the deterioration function of bolt prestress loss. The uniaxial creep test is performed on specimens with different joint angles, and the results show that the prestress loss time in anchor rods decreases linearly with increasing stress level. With increasing stress level, the time of prestress loss decreases linearly with the increase in stress level. With increasing axial load, the deformation caused by the transverse expansion stress of the specimen can offset the compression deformation of the prestressed anchor rod. The relationship between prestress loss in anchors and creep of rock is solved theoretically, and the stability criterion for anchor jointed rock is proposed. The results of this study provide a scientific reference for anchor design of deep jointed rock mass.

\section{Introduction}

During the development and construction of the SichuanTibet Railway challenges related to, a high density distribution of fault zones, high in situ stress states, and weak rock mass were very common $[1,2]$. Eighteen fault zones exist in the Lhasa-Linzhi Railway project region alone. This region contains the Bayu tunnel, which is $13037 \mathrm{~m}$ long and more than $2000 \mathrm{~m}$ deep, and the Dagala Tunnel, which is $1760 \mathrm{~m}$ deep and contains weak and fractured rock masses. Ageing and a large degree of deformation of the Dagala Tunnel under high in situ stress is apparent [3-7].

From a practical engineering standpoint, the creep characteristics of jointed rock masses under high in situ stress and the anchorage mechanism of prestressed bolts have been widely discussed. Zhao [8-10] performed uniaxial creep tests on anchored and nonanchored rock masses. Their experiments analysed the differences in the creep thresholds and the difference in long-term strength between anchored and nonanchored specimens to establish a creep model.
Wang et al. [11] studied the coupling effect between rock creep and the reduction of force in prestressed anchor cables ("prestress loss"). They established creep constitutive and relaxation equations, which reflect the anchor-rock coupling effect. Furthermore, they derived the calculation model for anchor prestress loss through the relaxation equation of the model. Grgic [12] analysed the elastic-plastic and viscoelastic failure of rigid multivoid rocks. Subsequently, a constitutive model conforming to the failure mode was proposed based on the unified theory of inelastic flow. Wang et al. [13] determined the relationship between force changes in prestressed anchor cables and the main parameters of rock mass creep based on the coupling effect model of creep deformation and the prestress loss of anchored rock mass. By the comparative analysis of theory and simulation, the specific causes of the errors were obtained, and the optimal design of the initial prestressing value applied to the anchor cables was proposed.

Despite numerous studies on the coupling effect between creep deformation of bolted rock masses and the prestress 
loss in bolts, the mechanism of this coupling effect remains unclear. The coupling effect model of creep deformation and prestress loss in anchor bolts developed in the studies described above are concerned with slope engineering and only consider the axial compressive deformation of rock mass under the action of anchor prestress loads. This model cannot solve the problem of prestressed loss in anchor rods caused by rock mass creep deformation due to surrounding rock pressure in tunnel engineering. In this study, the coupling effect between creep deformation and prestress loss in bolt jointed rock subject to external pressure is systematically evaluated by means of theoretical analysis and laboratory tests.

\section{Establishment of the Coupling Effect Model between Creep Deformation and Prestress Loss}

A number of engineering studies show that the instabilities and failures of rock masses are closely related to internal joints, crack development, expansion, and penetration. In this study, a rock mass with a single joint and anchor is analysed. Three kinds of joint inclination angles were used to analyse the coupling effect between creep deformation characteristics of rock mass with different joint angles and the prestress loss in the anchor [14]. Chen and Egger [15] proposed a new model of anchored joints, based on the rheological model of Sharma and Pande [16]. The model is divided into rock mass and joint parts, which are connected in series by the generalized Kelvin model, and the whole creep of the model is divided into compact rock mass. The sum of the deformation and joint deformation is shown in Figure 1.

The general Kelvin model is used in the rheological model of rock mass, which consists of a spring and a Kelvin model in series. Its constitutive equation is as follows:

$$
\begin{aligned}
\frac{\eta_{k}}{E_{h}+E_{k}} \dot{\sigma}_{k}+\sigma_{k} & =\frac{E_{h} E_{k}}{E_{h}+E_{k}} \varepsilon_{k}+\frac{\eta_{k} E_{k}}{E_{h}+E_{k}} \dot{\varepsilon}_{k}, \\
\frac{\eta_{j k}}{E_{j h}+E_{j k}} \dot{\sigma}_{j k}+\sigma_{j k} & =\frac{E_{j h} E_{j k}}{E_{j h}+E_{j k}} \varepsilon_{j k}+\frac{\eta_{j k} E_{j k}}{E_{j h}+E_{j k}} \dot{\varepsilon}_{j k},
\end{aligned}
$$

where $E_{h}, E_{k}$, and $\eta_{k}$ are the component parameters of rock mass; $E_{j h}, E_{j k}$, and $\eta_{j k}$ are the joint component parameters; $\sigma_{k}$ and $\varepsilon_{k}$ are the stress and strain of rock mass; and $\sigma_{j k}$ and $\varepsilon_{j k}$ are the stress and strain of joint part.

For a homogeneous rock mass with an even distribution of the prestressing force in the free section of the bolt, the elastic modulus of the bolt body can be equivalently transformed into the elastic modulus of the bolt body:

$$
\begin{gathered}
E_{s}=\frac{E_{1} A_{s}}{A_{r}}, \\
E_{j s}=\frac{E_{1} A_{s}}{A_{r}},
\end{gathered}
$$

where $E_{1}$ is the elastic modulus of anchor; $A_{s}$ is the lateral cross-sectional area of the anchor body; and $A_{r}$ is the cross- sectional area of the rock mass in the lateral anchorage of the anchor body.

The function for setting the loss modulus of the anchor rod with time is $y=a t+b$ and is used to characterize the extent of axial stress versus lateral stress on the lateral anchor. $E_{s}^{\prime}=E_{s}(a t+b)$, when $t=0, E_{s}^{\prime}=E_{s}$, then $b=1$, $E_{s}^{\prime}=E_{s}\left(a^{\prime} t+1\right)$; and then $E_{j s}^{\prime}=E_{j s}\left(a^{\prime} t+b\right)$, when $t=0$, $E_{s}^{\prime}=E_{j s}$, then $b=1, E_{s}^{\prime}=E_{j s}\left(a^{\prime} t+1\right)$ :

$$
\begin{aligned}
\sigma & =\sigma_{k}=\sigma_{j k}, \\
\varepsilon & =\varepsilon_{k}+\varepsilon_{j k}, \\
\varepsilon_{k} & =e^{-\left(F_{1} t+\left(H_{1} t^{2} / 2\right)\right)}\left[G_{1}+E_{1} t\left(1+\frac{F_{1} t}{2}+\frac{H_{1} t^{2}}{6}\right)\right], \\
\varepsilon_{j k} & =e^{-\left(F_{2} t+\left(H_{2} t^{2} / 2\right)\right)}\left[G_{2}+E_{2} t\left(1+\frac{F_{2} t}{2}+\frac{H_{2} t^{2}}{6}\right)\right],
\end{aligned}
$$

where $E_{2}=\left(\sigma_{c} / B_{2}\right), \quad F_{2}=\left(D_{2} / B_{2}\right), \quad H_{2}=\left(C_{2} / B_{2}\right)$, $G_{2}=\left(\sigma_{c} / E_{j h}+E_{j s}\right), \quad B_{2}=\left(\eta_{j k} E_{j k} / E_{j h}+E_{j k}\right), \quad D_{2}=\left(E_{j h}\right.$ $\left.E_{j k}+\eta_{j k} E_{j s} a / E_{j h}+E_{j k}\right)+E_{j s}$, and $C_{2}=E_{j s} a^{\prime}$, where $E_{1}=\left(\sigma_{c} / B_{1}\right), \quad F_{1}=\left(D_{1} / B_{1}\right), \quad H_{1}=\left(C_{1} / B_{1}\right), \quad\left(\sigma_{c} / E_{h}+E_{s}\right)$ $=G_{1}, \quad B_{1}=\left(\eta_{k} E_{k} / E_{h}+E_{k}\right), \quad D_{1}=\left(E_{h} E_{k}+\eta_{k} E_{s} a / E_{h}+E_{k}\right)$ $+E_{s}$, and $C_{1}=E_{s} a$ :

$$
\begin{aligned}
\varepsilon= & e^{-\left(F_{1} t+\left(H_{1} t^{2} / 2\right)\right)}\left[G_{1}+E_{1} t\left(1+\frac{F_{1} t}{2}+\frac{H_{1} t^{2}}{6}\right)\right] \\
& +e^{-\left(F_{2} t+\left(H_{2} t^{2} / 2\right)\right)}\left[G_{2}+E_{2} t\left(1+\frac{F_{2} t}{2}+\frac{H_{2} t^{2}}{6}\right)\right] .
\end{aligned}
$$

\section{Uniaxial Creep Test of Prestressed Anchored Jointed Rock Mass}

3.1. Test System and Specimen Preparation. The content of this section describes the uniaxial compression creep test, the loading system, and the data acquisition system indicated in Figure 2.

The loading system uses the microcomputer-controlled electrohydraulic servo three-axis tester obtained from the Civil Engineering Test Center of the Liaoning Technical University. The overall stiffness of the tester is over $10 \mathrm{GN} /$ $\mathrm{m}$, the maximum axial load achievable is $2000 \mathrm{kN}$, and the effective range of force measurement is $40-2000 \mathrm{kN}$. The resolution of the force measurement is $20 \mathrm{~N}$, with $1 \%$ accuracy, and the maximum confining pressure is $100 \mathrm{MPa}$, with $2 \%$ accuracy.

The unstructured rock mass and jointed rock mass for the specimen base are made of cement mortar consisting of 42.5 $\mathrm{MPa}$ ordinary Portland cement with river sand used in the ratio of $1: 2$ cement: sand. The anchor material used is HRB400 steel with a diameter of $10 \mathrm{~mm}$, length of $160 \mathrm{~mm}$, thread length of $15 \mathrm{~mm}$, and yield strength of $400 \mathrm{MPa}$. The model as a whole is a cube test piece with a side length of $150 \mathrm{~mm}$. The joint was $150 \mathrm{~mm}$ long, $50 \mathrm{~mm}$ wide, and $5 \mathrm{~mm}$ thick, with inclination angles of $30^{\circ}, 60^{\circ}$, and $90^{\circ}$ on either 


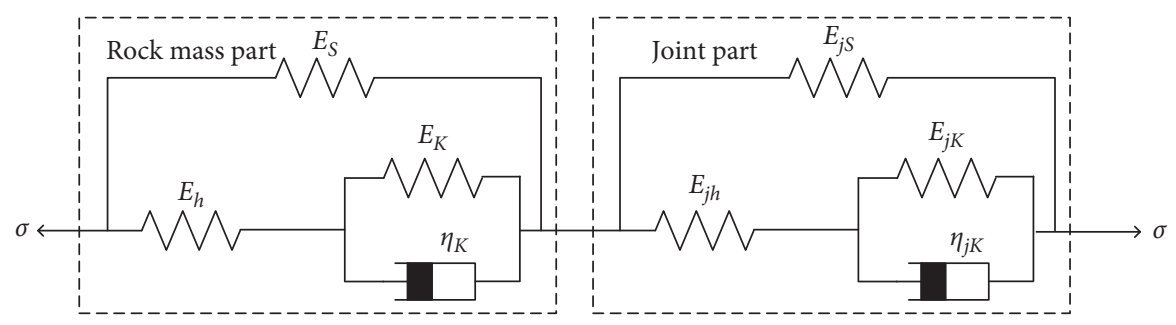

Figure 1: Coupling effect model of creep deformation and anchor prestress loss of anchored rock mass.

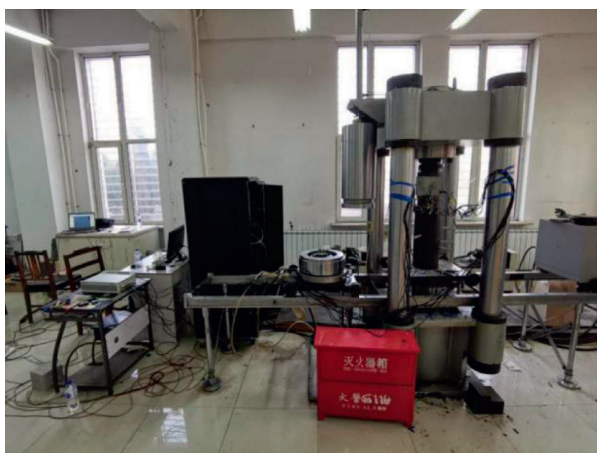

FIgure 2: Physical map of the test system.

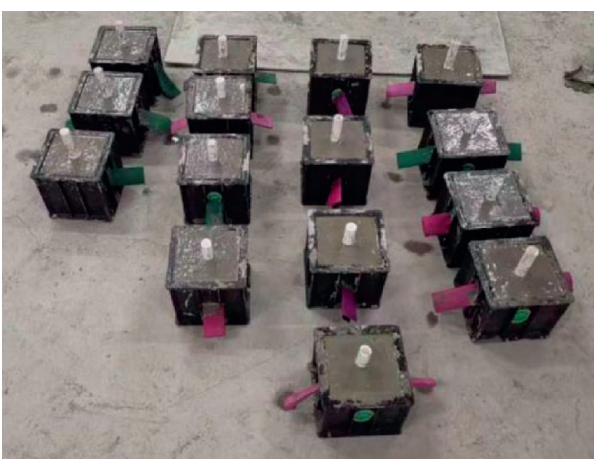

FIgURe 3: Production of specimens.

sides of the mould. The test piece and the joint test piece are shown in Figures 3 and 4, respectively.

The tests were carried out as follows:

(1) Strain gauges were attached longitudinally and transversely on both sides of the test piece to measure the axial and lateral creep behaviour of the test piece. A force measuring ring is placed under the base plate of the specimen to measure the application and variation of the prestress value of stress in the anchor rod.

(2) The strain gauge was attached along the joint surface to measure the joint shear deformation behaviour.

The mechanical parameters of the test specimens, determined through the relevant conventional methods, are shown in Table 1.

3.2. Test Methods. A uniaxial creep test was carried out on the $30^{\circ}, 60^{\circ}$, and $90^{\circ}$ dip joint prestressed anchor specimens.

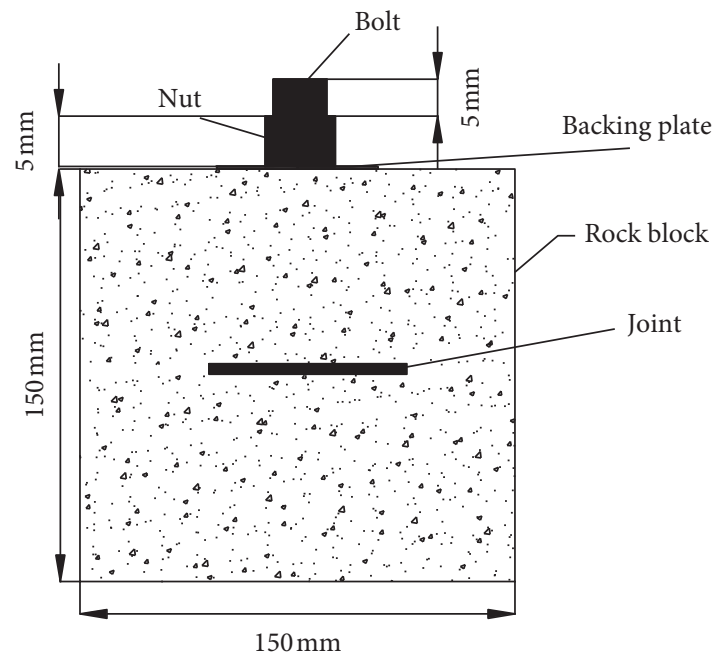

FIgURE 4: Diagram of typical joint specimens.

The loading rate is controlled ( $500 \mathrm{~N} / \mathrm{s}$ ) to $2 \mathrm{MPa}, 4 \mathrm{MPa}$, and $6 \mathrm{MPa}$, for the respective tests, and then kept constant for $10 \mathrm{~h}$. The creep test loading method considers the effect of creep deformation occurring in a short time, and the specimen is loaded by single-stage dead load creep.

3.3. Test Results and Analysis. In order to explore the longitudinal creep behaviour of rock mass with anchor joints, the creep variable curve with time is drawn and is shown in Figure 5:

(1) Under the action of each stress level, the $30^{\circ}, 60^{\circ}$, and $90^{\circ}$ dip joint specimens exhibit three stages of deformation, namely, transient deformation, decay creep, and steady-state creep with creep variables at each stage. It increases with increase in the stress levels.

(2) As the joint angle increases, the instantaneous deformation, attenuation creep, and steady-state creep of the specimen increase first and decrease subsequently. After the attenuation creep phase of the specimen, the creep rate gradually decreases until it finally stabilizes.

The lateral creep behaviour of anchor jointed specimens is shown in Figure 6:

(1) As Figure 6 shows, the specimen has a compressive stress because of the prestressed anchoring action. As the axial load is applied, "expansion" stress occurs. 
TABle 1: Mechanical parameters of test piece.

\begin{tabular}{lccccc}
\hline $\begin{array}{l}\text { Specimen } \\
\text { parameters }\end{array}$ & Uniaxial compressive strength & \multicolumn{2}{c}{ Mechanical parameters } & \multicolumn{2}{c}{ Elastic modulus } \\
$(\mathrm{MPa})$ & $\begin{array}{c}\text { Poisson's } \\
\text { ratio }\end{array}$ & $\begin{array}{c}\text { Cohesion } \\
(\mathrm{MPa})\end{array}$ & $\begin{array}{c}\text { Internal friction angle } \\
\left({ }^{\circ}\right)\end{array}$ \\
\hline Average value & 15.9 & 2.10 & 0.19 & 7.12 & 28.8 \\
\hline
\end{tabular}

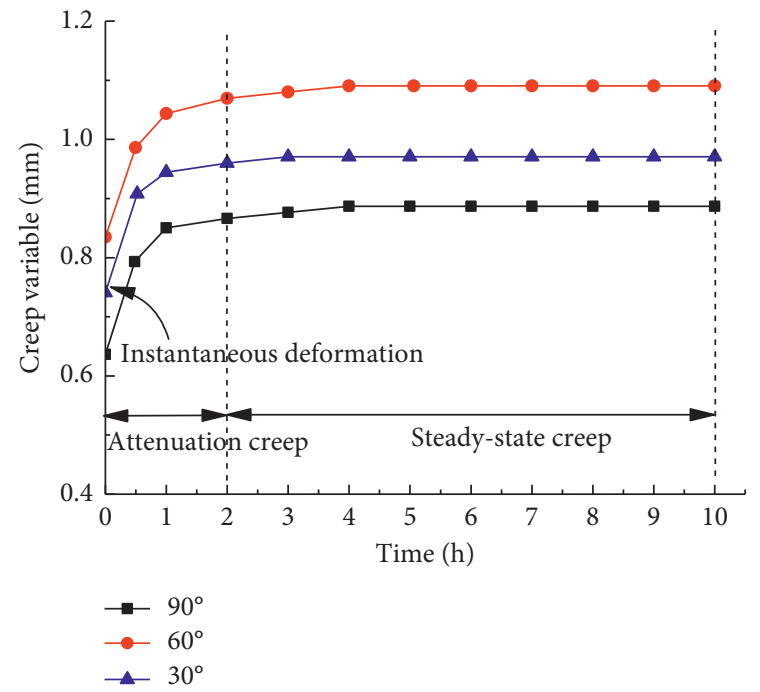

(a)

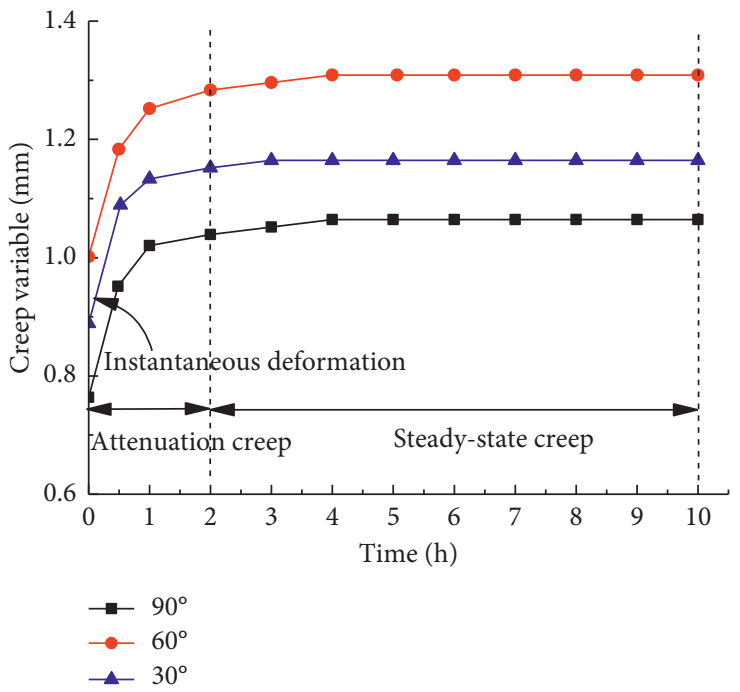

(b)

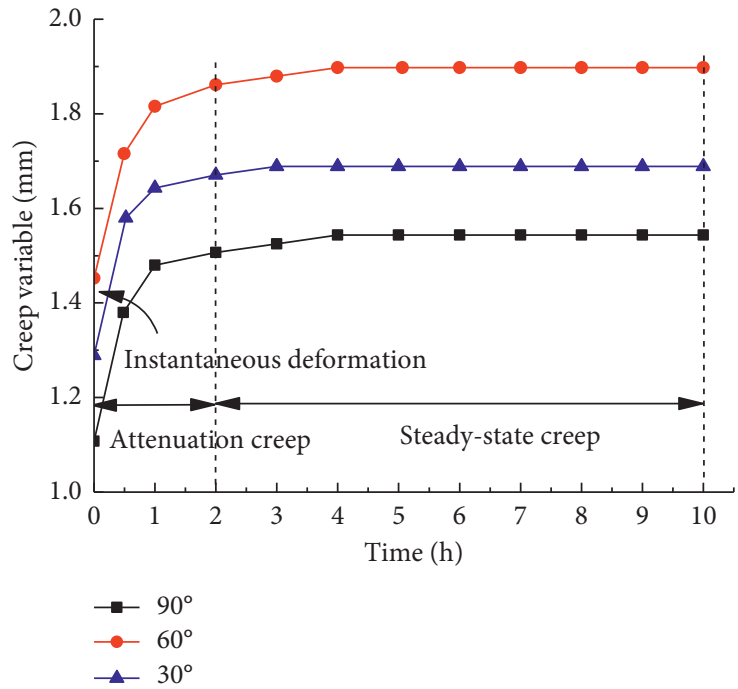

(c)

Figure 5: Longitudinal creep curve of anchored joint specimens. (a) The stress is $2 \mathrm{MPa}$. (b) The stress is $4 \mathrm{MPa}$. (c) The stress is $6 \mathrm{MPa}$.

Owing to the fastening effect of the prestressed anchor, the lateral deformation of the jointed test piece is delayed. This is because the lateral expansion stress is greater than the compressive stress generated by the anchor prestress. After offsetting the prestressed anchoring effect, the instantaneous deformation phase, the initial creep phase, and the isokinetic creep phase occur.

(2) An increase in the stress level causes a corresponding increase in deformation at each stage. Moreover, when the inclination angle decreases, the proportion of the attenuation creep increases and the proportion of instantaneous deformation decreases. The instantaneous deformation, attenuated creep, and steady-state creep of specimens increase first and then decrease. With a decrease in the dip angle, the difference in transverse creep between the angles decreases rapidly. This shows that a decrease in the angle between the bolt and the joint causes a more prominent anchorage effect of the bolt on the specimen. Compared to the variation of the difference in the longitudinal creep, the transverse 


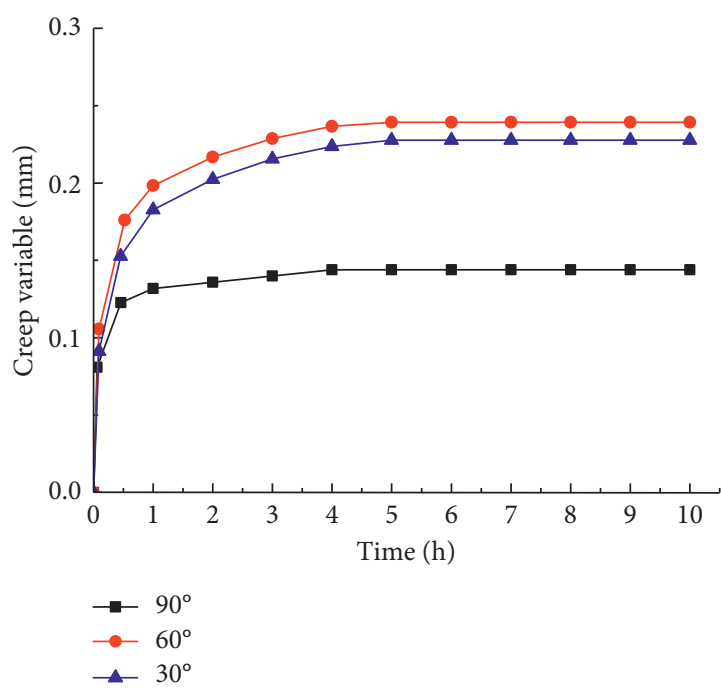

(a)

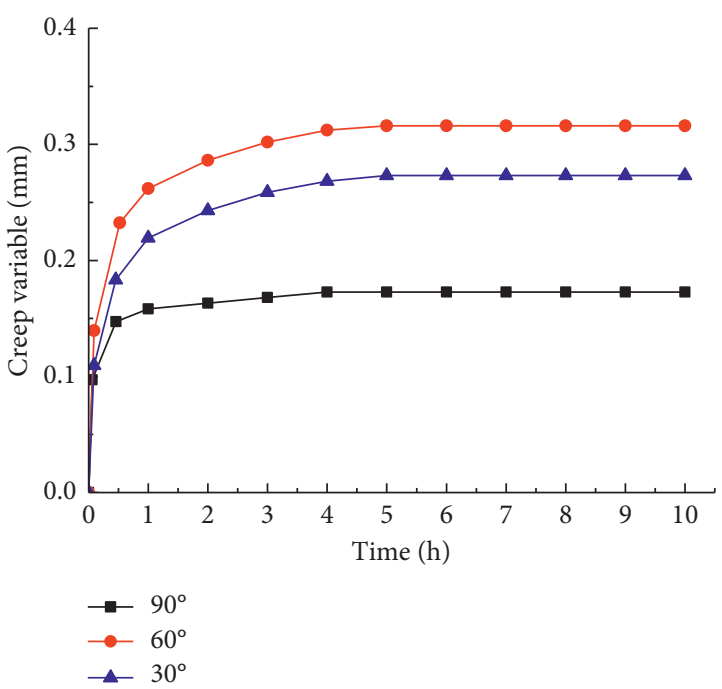

(b)

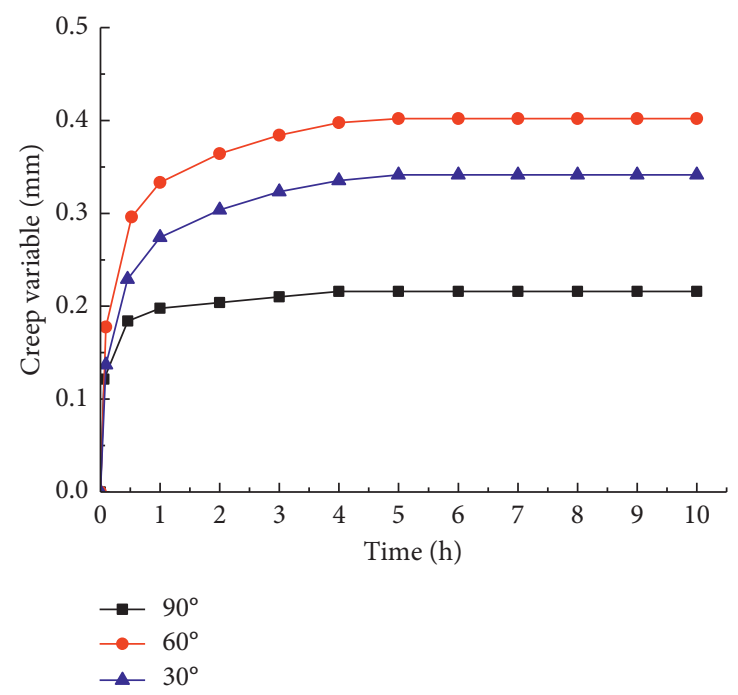

(c)

Figure 6: Transverse creep curve of anchored joint specimen. (a) The stress is $2 \mathrm{MPa}$. (b) The stress is $4 \mathrm{MPa}$. (c) The stress is $6 \mathrm{MPa}$.

resistance of the prestressing bolt to the creep deformation is greater than that of the corresponding longitudinal creep resistance.

Prestress loss behaviour of anchored joint specimens is shown in Figure 7.

As the axial load is applied, the specimen is deformed. This causes the prestress in the bolt to rapidly decrease from $20 \mathrm{kPa}$ to $0 \mathrm{kPa}$ with loss time corresponding to the lateral deformation time of the test piece. As the stress level increases, the prestress loss time approaches a linear decrease. As the joint angle decreases, the bolt prestress loss time decreases first and increases subsequently.

\section{Creep Model Parameters and Prestress Loss-Related Parameters}

Using the mathematical optimization software $1^{\text {st }}$ Opt, which is based on the quasi-Newton and the general global optimization approaches, the data obtained from the creep test and the parameters of creep constitutive model equation (4) were analysed. Furthermore, $2 \mathrm{MPa}$ was used as the basis to obtain relevant parameters. As shown in Table 2, the correlation coefficient is high, indicating that the model is reliable. In addition, Figure 8 shows a comparison of the test and the model.

Based on our results, the prestress loss curves of the anchored rock mass are analysed as shown in Figure 9.

It can be seen from Figure 9 that the elastic modulus of the anchor rod decreases linearly with time, and the decline is the fastest when the joint angle is $60^{\circ}$, indicating that the elastic modulus of the anchor rod is the most sensitive when the joint angle is $60^{\circ}$.

The relationship between rebound value of anchorage zone and time is shown in Figure 10.

As shown in Figure 10, the rebound deformation of the anchor end varies linearly. As the stress level increases, the springback deformation time of the joint specimens at each 


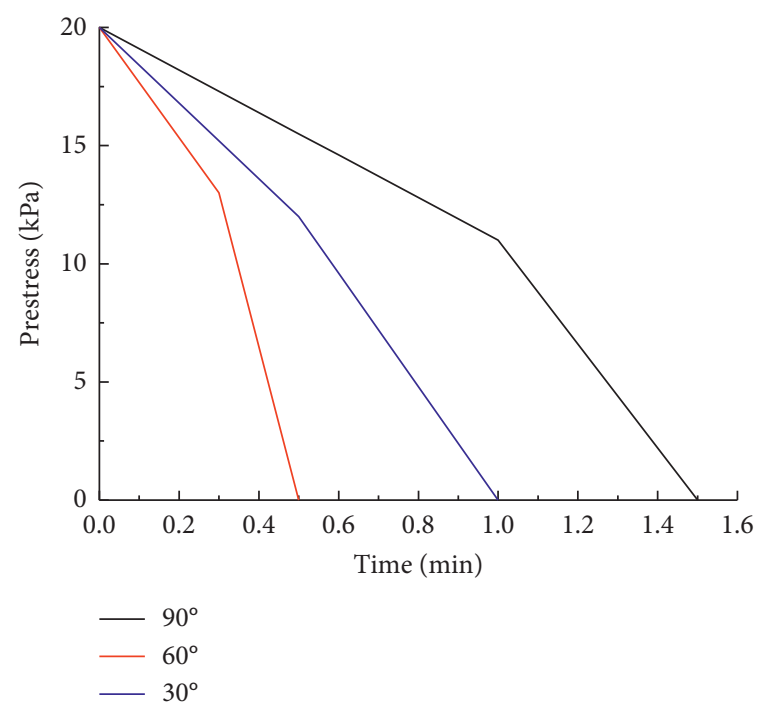

(a)

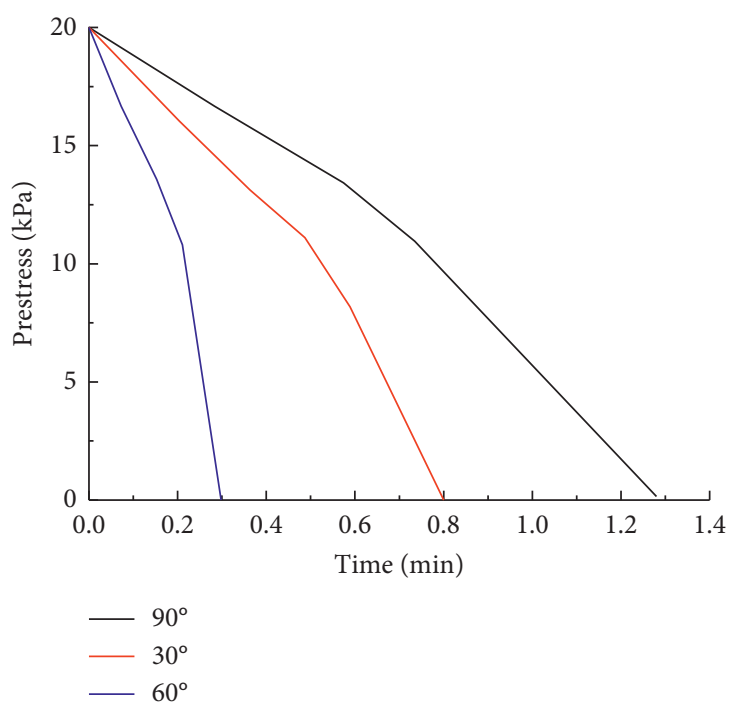

(b)

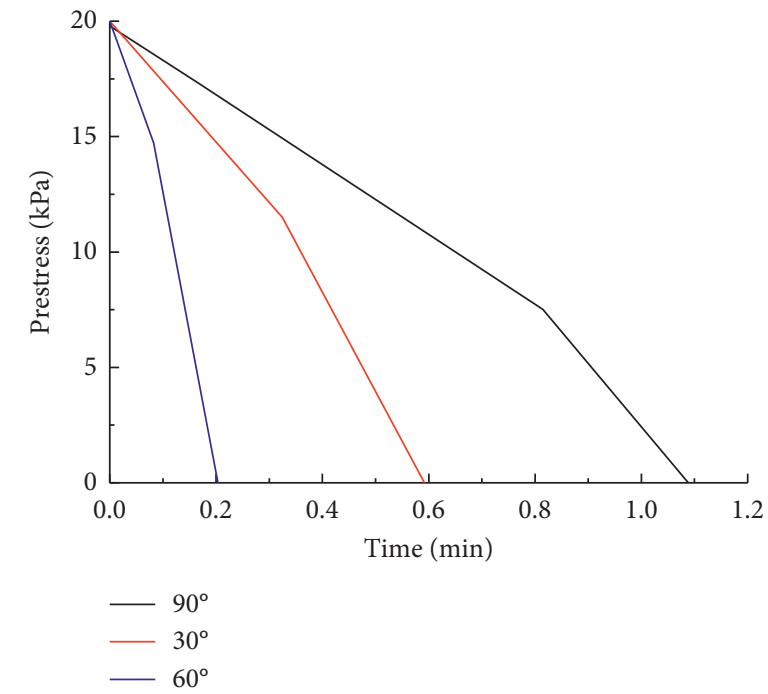

(c)

Figure 7: Prestress loss curve. (a) The stress is $2 \mathrm{MPa}$. (b) The stress is $4 \mathrm{MPa}$. (c) The stress is $6 \mathrm{MPa}$.

TABLE 2: Coupling effect model parameters of creep deformation and prestress loss of jointed and anchored rock mass.

\begin{tabular}{lccc}
\hline Joint dip angle $\left(^{\circ}\right)$ & 90 & 60 & 30 \\
\hline$E_{h}(\mathrm{MPa})$ & 22081 & 4450 & 9467 \\
$E_{k}$ & 30781 & 13920 & 18712 \\
$\eta_{k}$ & 36187 & 21930 & 26404 \\
$E_{j h}$ & 3677 & 10 & 160 \\
$E_{j k}(\mathrm{MPa} * \mathrm{~h})$ & 20195 & 9819 & 15281 \\
$\eta_{j k}(104047$ & 70265 & 77614 \\
$a$ & -0.11 & -0.05 & -0.054 \\
$a^{\prime}$ & -0.06 & -0.14 & 0 \\
Correlation coefficient $R$ & 0.96 & 0.93 & 0.97 \\
\hline
\end{tabular}

angle decreases. As the inclination decreases, the rate of decrease of the rebound curve increases first and decreases subsequently; however, the deformation time of the rebound decreases first and increases subsequently.
According to the elastic modulus loss value of the anchorage zone, the springback deformation of the tip is due to the lateral stress of the prestressed anchor in the prestressed loss stage. The formula $\sigma=E_{s}^{\prime} \cdot \varepsilon$ is used to calculate the prestress loss value. $E_{s}=\left(E_{1} A_{s} / A_{r}\right), A_{s}=0.0000785 \mathrm{~m}^{2}$, and $A_{1}=0.01256 \mathrm{~m}^{2}$.

The change in the bolt elastic modulus is calculated, and the springboard deformation stress of the bolt is obtained by combining the rebound deformation value of the anchor end with time. From Figure 11, it can be seen that the longitudinal creep stress is caused by the applied prestress. The transverse stress component is larger than the prestress value, and the prestress loss occurs mostly during initial deformation phase. As the stress level increases, the prestress loss curve decreases linearly. The theoretically derived values of the bolt prestress loss curves under the three kinds of stress levels are close to the prestress loss test results. 


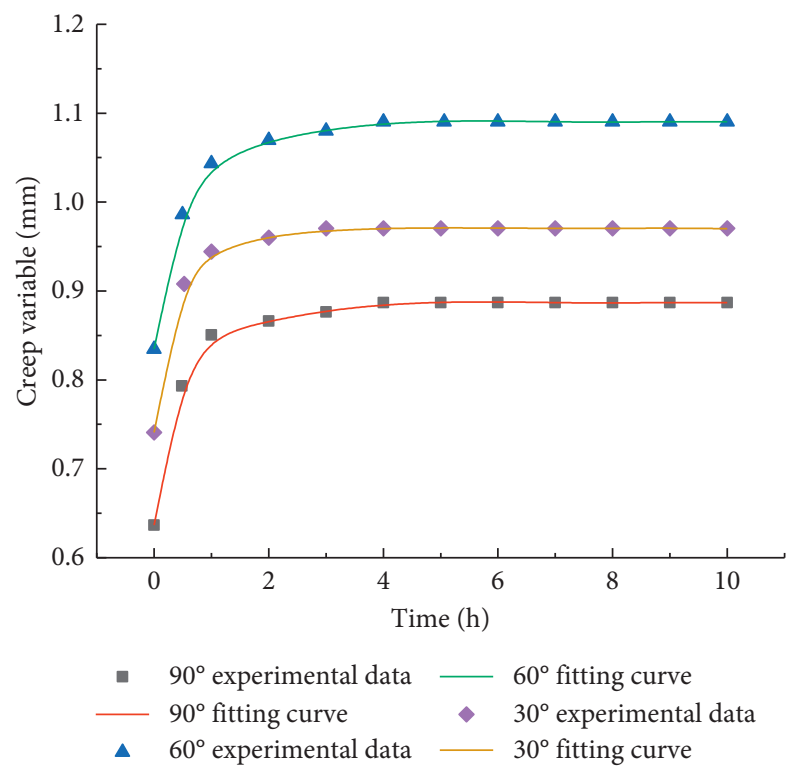

FIGURE 8: Comparison of fitting value of the creep model with experimental values.

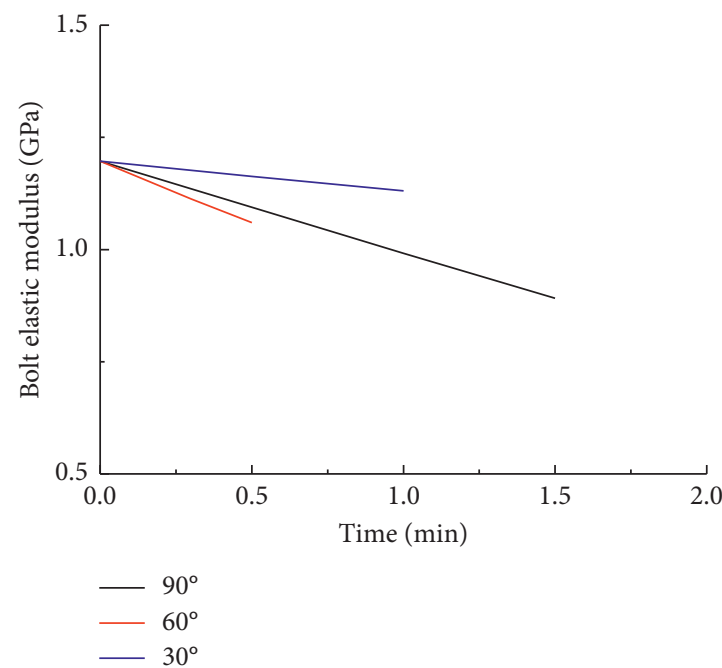

(a)

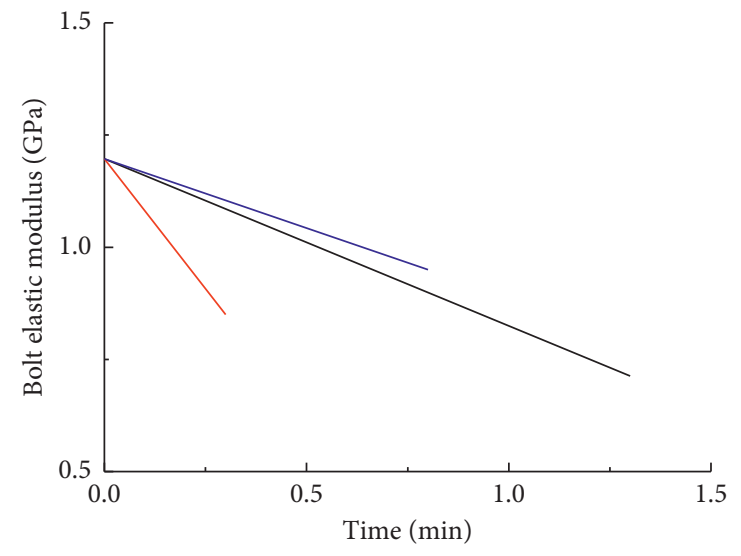

$-90^{\circ}$

(b)

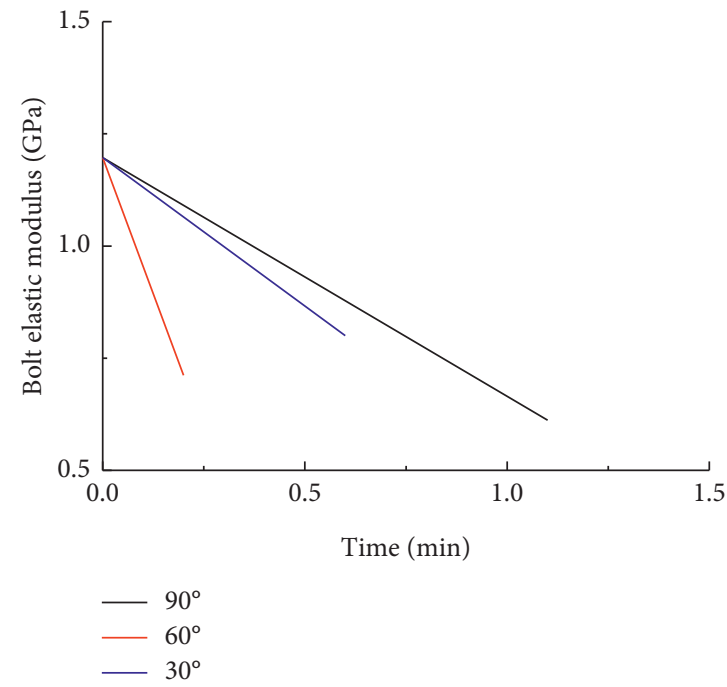

(c)

FIgURE 9: Joint model piece anchor elastic modulus loss curve. (a) The stress is $2 \mathrm{MPa}$. (b) The stress is $4 \mathrm{MPa}$. (c) The stress is $6 \mathrm{MPa}$. 

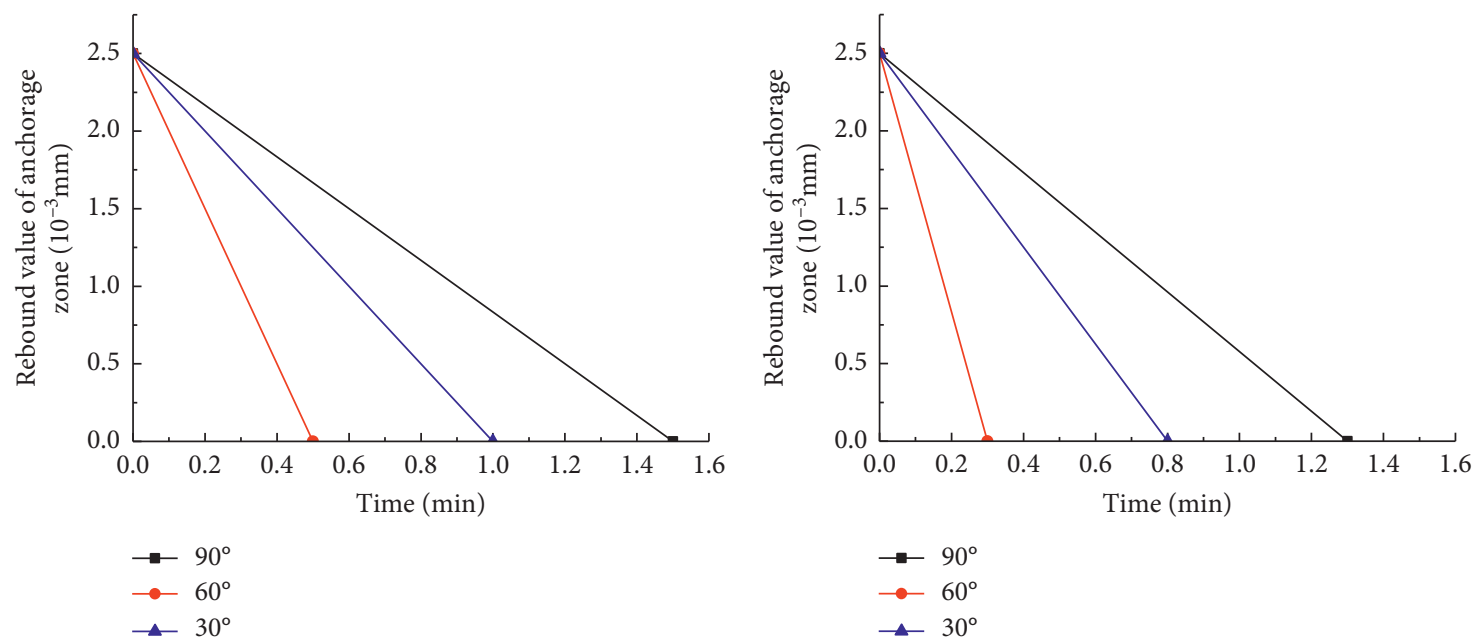

(a)

(b)

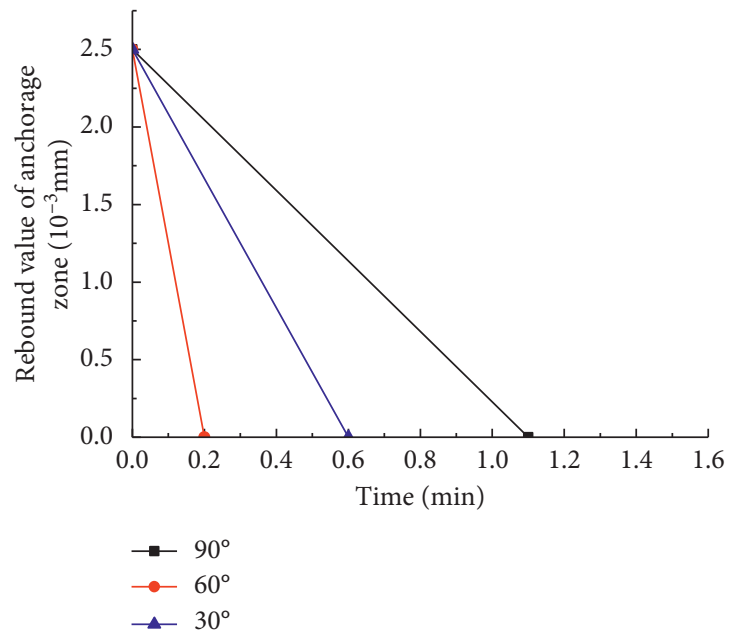

(c)

Figure 10: Rebound deformation curve of joint specimen anchorage zone. (a) The stress is $2 \mathrm{MPa}$. (b) The stress is $4 \mathrm{MPa}$. (c) The stress is $6 \mathrm{MPa}$.
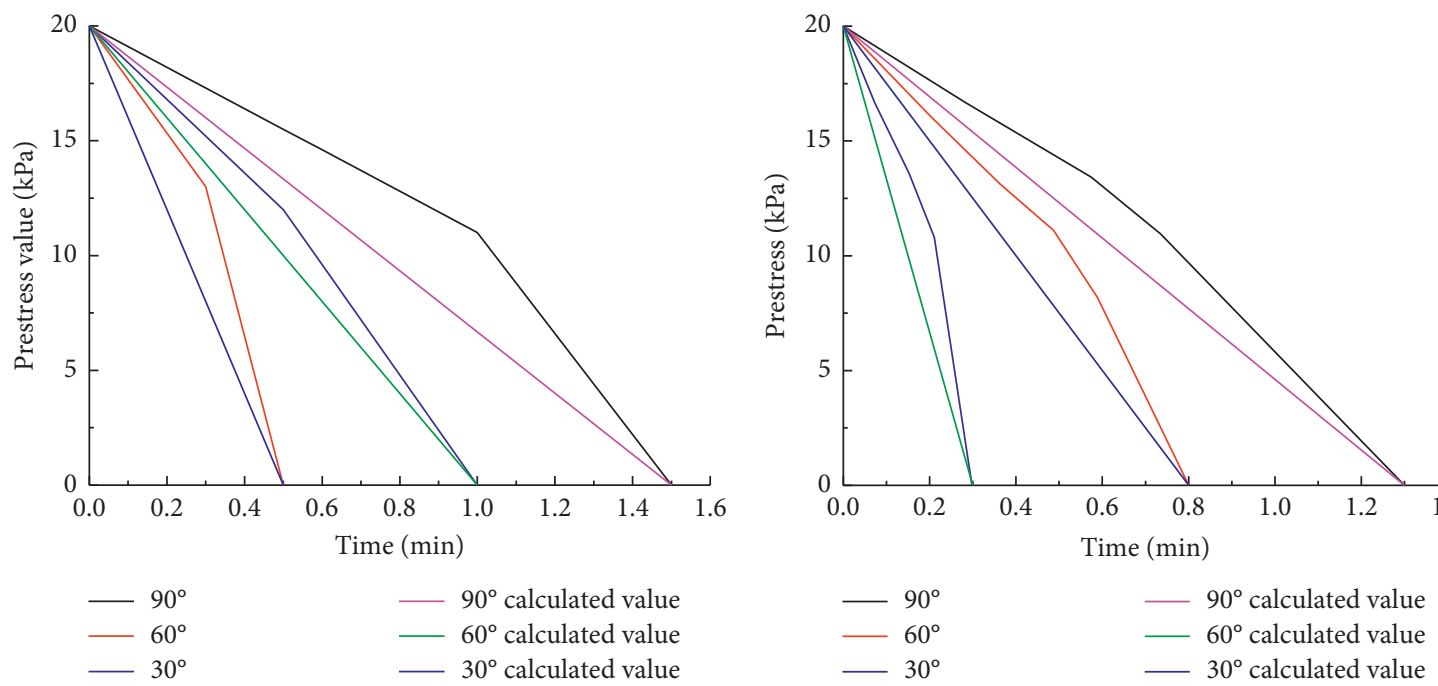

(a)

(b)

Figure 11: Continued. 


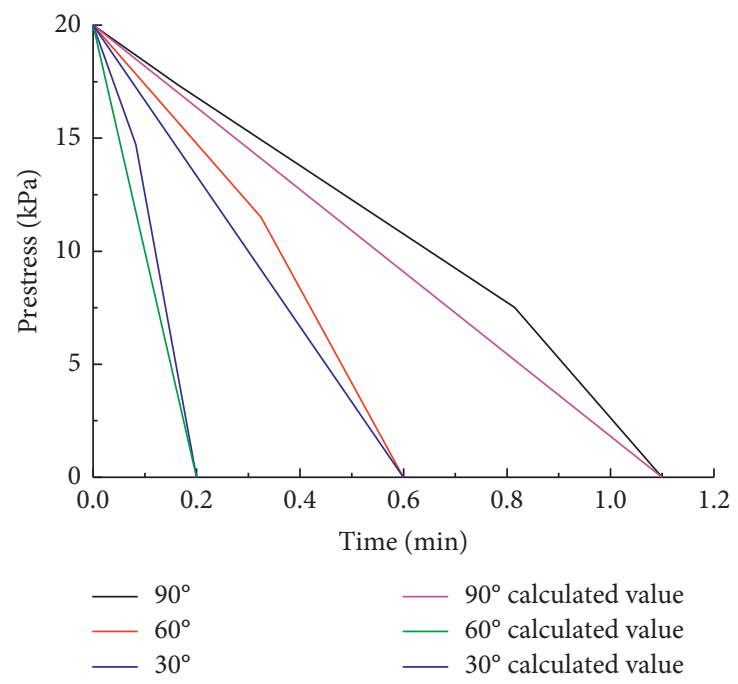

(c)

Figure 11: Comparison of stress level prestress loss curves. (a) The stress is $2 \mathrm{MPa}$. (b) The stress is $4 \mathrm{MPa}$. (c) The stress is $6 \mathrm{MPa}$.

This reflects the fact the prestress loss behaviour is caused by uniaxial compression creep deformation.

\section{Conclusion}

In this paper, the coupling effect between creep deformation of anchored rock and prestress loss in anchor bolts subject to external pressures is studied using test blocks to simulate rock mass characteristics and combining laboratory tests with theoretical research:

(1) The coupling effect model of creep deformation and anchor prestress loss for anchored rock masses subject to external pressure is established, and the calculation method of bolt prestress loss is proposed.

(2) By uniaxial creep tests on joints with different angles, it was found that the creep variables of the longitudinal and transverse stages of the joint specimen increased as stress level increases, and the prestress loss time of the bolt increases with the stress level. Thus, the linear progression is reduced. As the joint angle decreases, the magnitudes of axial and lateral creep variables first decrease and then increase. Furthermore, the lateral resistance creep deformation of the prestressed anchor is greater than the longitudinal creep resistance. In contrast, the bolt prestress loss time is first reduced and then increased.

(3) The coupling effect between creep deformation and anchor prestress loss in anchored rock has been explained. When the axial load increases, the transverse expansion stress of the specimen deforms correspondingly, which offsets the compressive stress of the prestressed anchor. The amount of compression deformation causes the bolt prestress to drop to zero. Owing to the presence of the prestress, the lateral initial deformation of the test piece is delayed. As the prestress reaches zero, the latter stage is assumed by the anchor rod. During this stage, the anchor supports the external load and restrains the creep of the rock mass.

\section{Data Availability}

All data generated or analysed during this study are included in this article.

\section{Conflicts of Interest}

The authors declare that they have no conflicts of interest.

\section{Acknowledgments}

The authors are grateful to the Fund Project (China) for funding this work. The authors also gratefully acknowledge the National Natural Science Foundation (51974146) and Liaoning Natural Science Foundation (2019-ZD-0042) for their support.

\section{References}

[1] F. Pellet and P. Egger, "Analytical model for the mechanical behaviour of bolted rock joints subjected to shearing," Rock Mechanics and Rock Engineering, vol. 29, no. 2, pp. 73-97, 1996.

[2] H. Li and H. Li, "Mechanical properties and acoustic emission characteristics of thick hard roof sandstone in Shendong coal field," International Journal of Coal Science \& Technology, vol. 4, no. 2, pp. 147-158, 2017.

[3] D. W. Ding, S. W. Bai, and G. Y. Luo, "Analysis on the load losses of prestressed rock cablle bolts," Journal of Engineering Geology, vol. 3, no. 1, pp. 65-69, 1995.

[4] A. M. Chen, J. C. Gu, J. Shen, and Z. Q. Ming, "Model testing research on the variation of tension force of anchor cable with time in reinforcement of soft rocks," Chinese Journal of Rock Mechanics and Engineering, vol. 21, no. 2, pp. 251-256, 2002. 
[5] H. Y. Zhu, Y. Q. Shang, X. M. Lu, and H. B. Wang, "Coupling analysis of long-term prestress loss and slope creep," Chinese Journal of Geotechnical Engineering, vol. 27, no. 4, pp. 464467, 2005.

[6] Y. Zhong, Y. Liu, and Z. X. Zheng, "Comprehensive treatment technology for large deformation of surrounding rock in Chuanzang road tunnel," Southwest Highway, vol. 4, no. 1, pp. 129-132, 2009.

[7] T. Feng, L. Jiang, C. D. Wang, D. Wang, and G. Z. Zhang, "Application of engineering geological analogy method in classification of surrounding rock of Sichuan Tibet railway tunnel," Sichuan Architecture, vol. 37, no. 2, pp. 139-141, 2017.

[8] T. B. Zhao, Y. L. Tan, S. S. Liu, and Y. X. Xiao, "Analysis of rheological properties and control mechanism of anchored rock," Rock and Soil Mechanics, vol. 33, no. 6, pp. 1730-1734, 2012.

[9] S.-Q. Yang, M. Chen, H.-W. Jing, K.-F. Chen, and B. Meng, "A case study on large deformation failure mechanism of deep soft rock roadway in Xin'an coal mine, China," Engineering Geology, vol. 217, no. 4, pp. 89-101, 2017.

[10] R. Yuan and B. Shi, "Acoustic emission activity in directly tensile test on marble specimens and its tensile damage constitutive model," International Journal of Coal Science \& Technology, vol. 5, no. 3, pp. 295-304, 2018.

[11] Q. B. Wang, C. Zhang, H. Wang et al., "Study of coupling effect between anchorage force loss of prestressed anchor cable and rock and soil creep," Rock and Soil Mechanics, vol. 35, no. 8, pp. 2150-2156, 2014.

[12] D. Grgic, "Constitutive modelling of the elastic-plastic, viscoplastic and damage behaviour of hard porous rocks within the unified theory of inelastic flow," Acta Geotechnica, vol. 11, no. 1, pp. 95-126, 2014.

[13] K. Z. Wang, H. Wu, and Y. F. Zhao, "Coupling between reduction of force in prestressed anchor cable and rock creep in deep-buried underground powerhouse," Chinese Journal of Rock Mechanics and Engineering, vol. 37, no. 6, pp. 1481-1488, 2018.

[14] S. H. Chen and G. N. Pande, "Rheological model and finite element analysis of jointed rock masses reinforced by passive, fully-grouted bolts," International Journal of Rock Mechanics and Mining Sciences \& Geomechanics Abstracts, vol. 31, no. 3, pp. 273-277, 1994.

[15] S.-H. Chen and P. Egger, "Three dimensional elasto-viscoplastic finite element analysis of reinforced rock masses and its application," International Journal For Numerical And Analytical Methods In Geomechanics, vol. 23, no. 1, pp. 61-78, 1999.

[16] K. G. Sharma and G. N. Pande, "Stability of rock masses reinforced by passive, fully-grouted rock bolts," International Journal of Rock Mechanics and Mining Sciences \& Geomechanics Abstracts, vol. 25, no. 5, pp. 273-285, 1988. 